\title{
A Developmentally Linked, Dramatic, and Transient Loss of Virus from Roots of Arabidopsis thaliana Plants Infected by Either of Two RNA Viruses
}

\author{
Pablo Lunello, Carmen Mansilla, Flora Sánchez, and Fernando Ponz \\ Centro de Biotecnología y Genómica de Plantas (CBGP, UPM-INIA). Autopista A-6, km 7. 28040 Madrid, Spain
}

Submitted 30 March 2007. Accepted 24 July 2007.

\begin{abstract}
Possible effects of host developmental stage on the amount of virus present in systemically infected plant tissues hitherto have received little attention. In this study, the pattern of virus accumulation over the plant lifespan has been examined in systemically invaded tissues of Arabidopsis thaliana infected by either of two distinct $(+)$ RNA viruses: Turnip mosaic virus, a member of Potyvirus, and Oilseed rape mosaic virus, a member of Tobamovirus. Quantitative analyses of virus coat protein and virus genomic RNA in roots versus aerial plant parts revealed generally sinusoidal temporal patterns of virus accumulation. In noninoculated leaves, a time period was found during which no virus accumulation was detected. This period was coincident with the approximately 7 days of inflorescence bud formation and differentiation. In roots, virion content reached high levels a few days after inoculation, dropping dramatically during the period of bud formation and quickly recovering after it. These results, together with electron microscopy observations, are consistent with loss of virions due to disassembly. Fluorescence observations of green fluorescent protein-tagged virus-infected root tissue also were consistent with a net loss of virus-specified proteins. Inoculations performed after the emergence of the inflorescence and on A. thaliana flowering-time mutants support the temporal link between observed changes in virus content and inflorescence bud formation. Different host-involving biochemical processes can be invoked to provide mechanistic clues, but no one of them alone seems sufficient to explain the complex patterns of tight temporal regulation of virus accumulation observed in these experiments.
\end{abstract}

Additional keyword: developmental stage, infected roots.

The successful systemic invasion of plants by infecting viruses is a complex process starting with the replication and accumulation of the virus in the first inoculated cells, followed by subsequent processes of cell-to-cell movement to nearby cells, loading into the plant vascular system (usually the phloem), vascular transport, downloading in distant tissues, and reinitiation of replication and accumulation, coupled again to cell-to-cell movement. Many detailed aspects of this general process have been unraveled, leading to the present view of the

Corresponding author: Fernando Ponz; Telephone: +34 913476887; Fax: +34 913573107; E-mail: fponz@inia.es

* The $\boldsymbol{e}$-Xtra logo stands for "electronic extra" and indicates additional information is available online. Three additional figures and one additional table are published online. need of multiple interactions between virus and host gene products, and a fine regulation of the different phases of the process (Boevink and Oparka 2005; Oparka and Santa Cruz 2000; Waigmann et al. 2004).

A widely accepted model of the global virus dispersion pattern within the plant links virus and photosynthate movement, thus identifying preferred sites (the photosynthate sinks) of virus invasion and efficient sources of new inoculum (the photosynthate sources) (Leisner and Howell 1993; Leisner and Turgeon 1993; Samuel 1934). Many experimental results support this model (Carrington et al. 1996; Palukaitis 1987). Most plant parts undergo photosynthate sink-to-source transitions as the plant grows; therefore, presumably, virus replication and spread are linked in some way to plant development. In fact, a close relationship between virus susceptibility of a given plant organ and its developmental stage was put forward several years ago and called "developmental resistance" (Leisner et al. 1993).

Certain aspects of the model of photosynthate transport-correlated virus movement have not received enough attention. In this model, permanent sink organs, such as roots and fruit (Dunford 2006), should be constantly receiving and accumulating virus; however, this supposition has not been tested. Also, the kinetics of virus accumulation in organs undergoing the transition (mostly leaves) would be predicted to be severely influenced by development. However, few data are available that speak to this prediction. Some of these data show the influence on virus movement of the dramatic changes in numbers and architecture of plasmodesmata in leaves of Nicotiana benthamiana as they undergo transition (Oparka et al. 1999; Roberts et al. 1997), or the ability of Potato spindle tuber viroid (PSTVd) to traffic from the bundle sheath to the mesophyll only in source leaves of N. tabacum (Qi et al. 2004).

We have addressed some of these questions using the plant experimental model system Arabidopsis thaliana as a host and two plant (+)RNA viruses with very different gene expression strategies: Turnip mosaic virus (TuMV), a member of Potyvirus producing its proteins through viral proteinase-mediated processing of a precursor polyprotein (Jenner et al. 2000); and Oilseed rape mosaic virus (ORMV), a member of Tobamovirus expressing its genome through the production of subgenomic RNAs (Aguilar et al. 1996; Melcher 2003). We and others recently and increasingly have been using these two viruses as two efficient pathogens of $A$. thaliana to study different aspects of plant-virus interactions (Dunoyer et al. 2004; Huang et al. 2005b; Kaneko et al. 2004; Leonard et al. 2004; Plante et al. 2004; Sato et al. 2005; Suehiro et al. 2004; Tan et al. 2005; Walsh and Jenner 2002; Whitham et al. 2003). We used a broad range of techniques to monitor the accumulation and 
spread of viruses in wild-type and developmental mutant plants. We observed that virus accumulation in different parts of the plant was tightly regulated by development. Virus accumulation in the roots displayed a surprising sinusoidal pattern which was consistent with observations of apparent virion physical disassembly and structural modification. A model explaining the main features of the process is proposed, with considerations of possible underlying mechanisms.

\section{RESULTS}

\section{Accumulation of virus capsid antigen is halted and} reversed in systemically invaded tissues.

Enzyme-linked immunosorbent assay (ELISA) time-course analyses were performed for the detection of viral capsid antigen in systemically infected tissues of plants inoculated with TuMV-UK1 or ORMV. The period analyzed covered 25 days from the day of virus inoculation (developmental stage 1.08) (Boyes et al. 2001). Disease development and senescence of the infected plants precluded further analyses after 25 days. Relative concentration ELISA (rcELISA) values are presented in Figure 1A and reveal significant similarities between results for the Potyvirus- and the Tobamovirus-infected plants.

In roots, capsid antigen increased for both viruses during the period 3 to 10 days after inoculation (dai), with TuMV capsid antigen accumulation slowing after 5 dai. A dramatic drop in accumulated root capsid antigen was detected between 10 and 13 dai, with the drop being notably more intense for TuMV. For 13 to 17 dai, capsid antigen increased and, for 17 to 25 dai, fell similarly for the two viruses. ORMV showed similar capsid antigen accumulation in roots and systemically infected leaves, probably reflecting a more efficient systemic movement from the initially inoculated leaves toward newly infected ones. TuMV capsid antigen accumulation in systemically infected leaves rose fairly steadily to 17 dai, though a trace of the two declines in root capsid antigen also was reflected in the leaf capsid antigen.

\section{The accumulation of green fluorescent protein expressed from TuMV also decreases temporarily in infected root tissue.}

The strong decline in rcELISA values for TuMV-infected root in the 10- to 13-dai period suggests not merely cessation of synthesis but actual disappearance of coat protein in all forms (capsid antigen). Therefore, it was of interest to examine another virus-expressed protein. No antibodies are available to us for any of the other native virus protein; therefore, we infected plants with a TuMV green fluorescent protein (GFP) cDNA clone. Fluorescence microscopy images obtained from the roots of $A$. thaliana plants infected with the GFP-tagged TuMV are shown in Figure 1B. The time points at which the roots were examined are the same as for rcELISA. The lowest fluorescence intensity was detected at 13 dai, corresponding to a time of minimum capsid antigen accumulation. The observed fluorescence increased again after 13 dai, reminiscent of the Figure 1A results and suggesting that a general loss of viral protein production took place during this period. No GFP-expressing construct was available for ORMV.

\section{Apparent virion disassembly occurs temporally in the roots of infected plants.}

A general reduction in viral protein production does not suffice to explain the drastic drop in rcELISA values in roots, because capsid antigen (i.e., various forms of capsid protein $[\mathrm{CP}])$ is expected to reflect the accumulation of a stable protein, and that protein resides mostly in a stable assembly, the virion. Any tenable explanation for the observed results must posit that capsid antigen either is largely removed from the roots to somewhere else in the plant during this period or is destroyed. A massive displacement of root virions is very difficult to examine experimentally and is quite unlikely, based on our observations. No increase in rcELISA values was detected in systemically infected leaves during the period of declining root rcELISA values (Fig. 1A). For TuMV, rcELISA values remained unchanged between 10 and 13 dai for systemically infected leaves and, for ORMV, actually dropped for leaf extracts as well as for root extracts.

In fact, virion counts strongly suggest that virions of both TuMV and ORMV are disassembled in root tissue in the 10- to 13-dai period, as would be predicted by the rcELISA results of Figure 1A. A comparison of results from Figure 1A and Supplemental Figure 1 online also suggests a more rapid recovery of rcELISA values than virion counts in the 13- to 17-dai period. Possibly ELISA detects CP molecules that have not yet been incorporated into particles.

If virions actually are disassembled in roots during the 10- to 13-dai period, it might be possible to detect dissociation intermediates. We analyzed virion images by electron microscopy (EM), measuring virion length and relative density. These measurements allowed us to calculate relative density values for
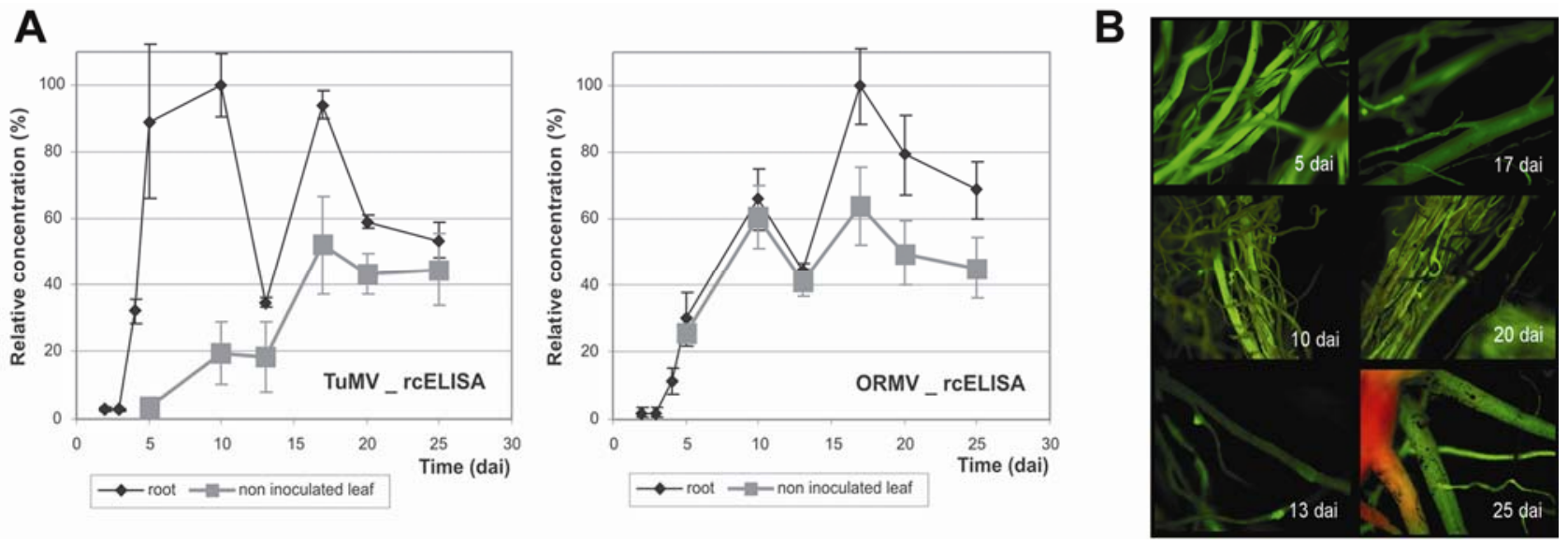

Fig. 1. A, Relative concentration enzyme-linked immunosorbent assay (rcELISA) of extracts from roots and noninoculated leaves for different time points covering a period of 25 days after inoculation (dai). Each curve was derived from four complete infection cycle experiments, and error bars correspond to the standard deviation for values averaged among six to nine plants of each time point per experiment. B, Fluorescence microscopy detection of green fluorescent protein expressed in roots from a Turnip mosaic virus-derived vector. Insets show the dai at which photographs were taken. 
virion images derived from samples from various timepoints (Fig. 2). In the case of TuMV, both average virion length and virion relative density paralleled the time-course patterns obtained for rcELISA, suggesting that, during the period of declining rcELISA values, virions were being disorganized in the roots in a process that involved both virion unpacking (relative density) and virion shortening (length). During this period, the typical 845-nm modal length of TuMV particles encapsidating full-length genomic RNA was reduced to $531 \mathrm{~nm}$ at 13 dai and to $552 \mathrm{~nm}$ at 17 dai. ORMV virions seemed to resist better the dissociation process. Tobamovirus virions encapsidating fulllength genomic RNAs are in the range of 300 to $320 \mathrm{~nm}$ long, and equivalent ORMV particles were 308 to $322 \mathrm{~nm}$ with a modal length of $317 \mathrm{~nm}$. At no time did we observe any length shortening of this type of particle. We observed, however, additional types of virus particles of approximately 65,150 , and 250 $\mathrm{nm}$. These kinds of particles have been described in other microscopy preparations of tobamoviruses. By comparisons to other tobamoviruses, we believe that the short particles correspond to encapsidated subgenomic RNAs (unpublished results). The less-than-full-length particles observed for the TuMV infections and ORMV infections differ because the former show a heterogeneous size distribution, whereas the latter show discrete size groups (results not shown). Although ORMV particles maintained their length over the 10- to 25 -dai time period, a progressive reduction of the relative density was evident (Fig. 2; Supplemental Fig. 2). The relative density image analyses indicated that, whereas TuMV seemed to recover its original compression degree to a certain extent, ORMV did not. This result would suggest that, in the case of the tobamovirus, some virion relaxation occurs but that this is insufficient to cause disassembly. At no time point did we observe any drop in the infectivity present in ORMV-infected roots. This was deduced from local lesion assays performed using root extracts to inoculate NNgenotype tobacco plants at different times. The assays showed that local lesion-inducing ability paralleled virion counts regardless of the relative densities of the virions. This suggested that any relaxation in virion structure was not affecting infectivity.

The assays showed that local lesion-inducing ability paralleled virion counts regardless of the relative densities of the virions.

\section{Appearance and disappearance of viral genomic RNA in roots.}

The reduction in rcELISA in roots at 10 to 13 dai for both viruses (Fig. 1A) suggests that virus genomic RNA similarly would decline. Results for reverse-transcriptase quantitative polymerase chain reaction (RT-qPCR) for both viruses are presented in Figure 3, using total RNA preparations as a source of template. Like the rcELISA results, the RT-qPCR results are generally sinusoidal. For TuMV, the peak values observed at 5 and 20 dai clearly are greater than the values observed for 10 to 17 dai and at 25 dai. In the case of the tobamovirus, the observed maxima and minima are not as dramatically different as those observed for TuMV.

\section{Temporal correlation of virus accumulation in roots and the floral bud formation.}

Our results show a similar sinusoidal variation in virus RNA and proteins for two taxonomically distinct viruses infecting $A$. thaliana. It seemed logical that this variation may be related to the plant developmental plan. For the ecotype used throughout the studies (RLD), the formation of the inflorescence buds took place during the period 10 to 17 dai, corresponding to declining or low values for rcELISA (Fig. 1A) and RT-qPCR (Fig. 3). The notion that the two phenomena are connected was tested with TuMV by three different approaches. In the first
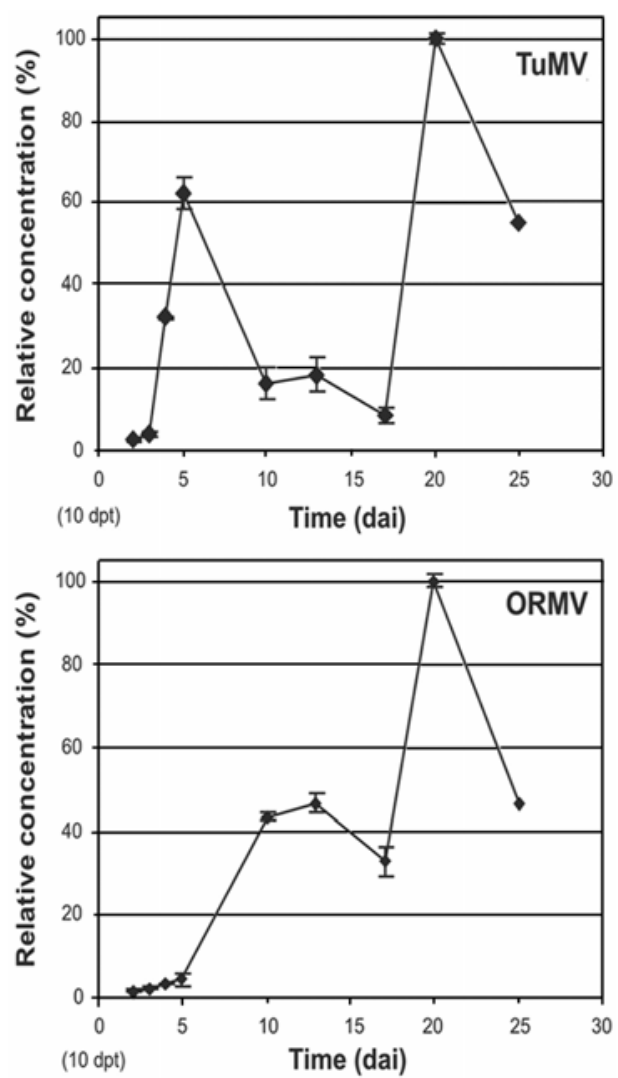

Fig. 3. Reverse-transcriptase quantitative polymerase chain reaction assays from RNA root extracts of infected plants. For each panel, virus genomic RNA was quantified, and the results were converted to a percentage of the maximum value found (i.e., at 20 days after inoculation [dai]).
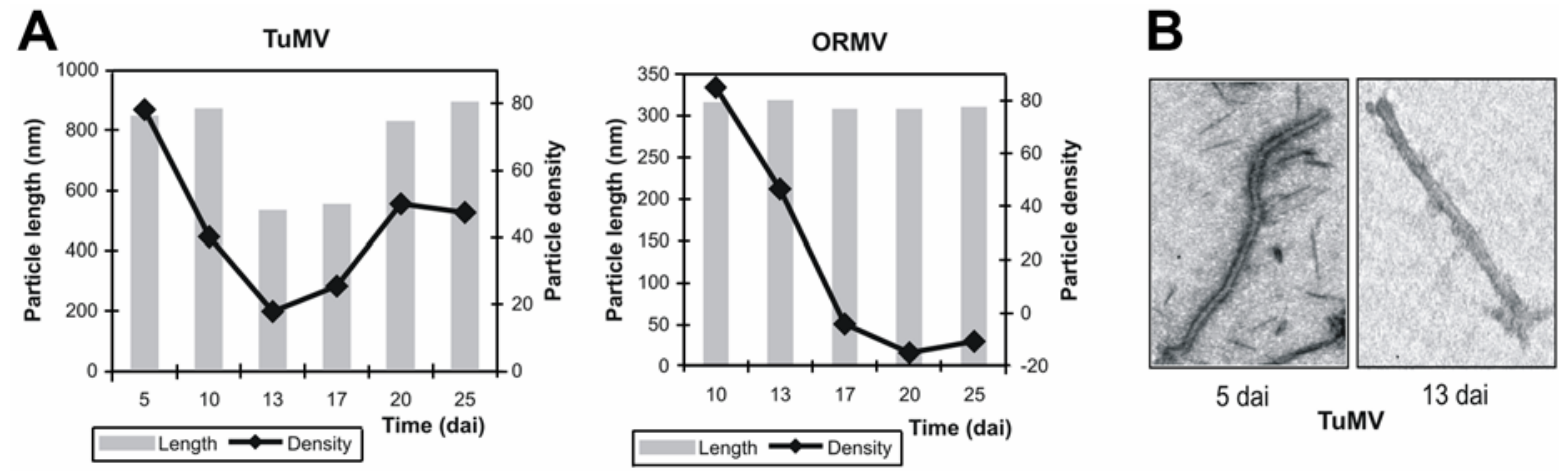

Fig. 2. Analysis of virion electron microscopy micrographs. A, Bars represent particle average length. Values in the graphs represent particle relative density. B, Samples of high-density (left) and low-density (right) virion micrographs of Turnip mosaic virus (TuMV) in root samples. 
approach, the time of virus inoculation in RLD was delayed 10 days. At this time, the inflorescence bud already had started forming. No drop or halt in rcELISA values was detected in roots or leaves, except slight ones at the end of the experiment (Fig. 4, top panel). The other two approaches involved the use of A. thaliana flowering-time mutants. The middle panel in Figure 4 shows the results obtained with the mutant early in short days (ESD7), a very early flowering-time mutant which already had formed the inflorescence bud at the normal time of

TuMV-UK1 delayed inoculation _ rcElISA

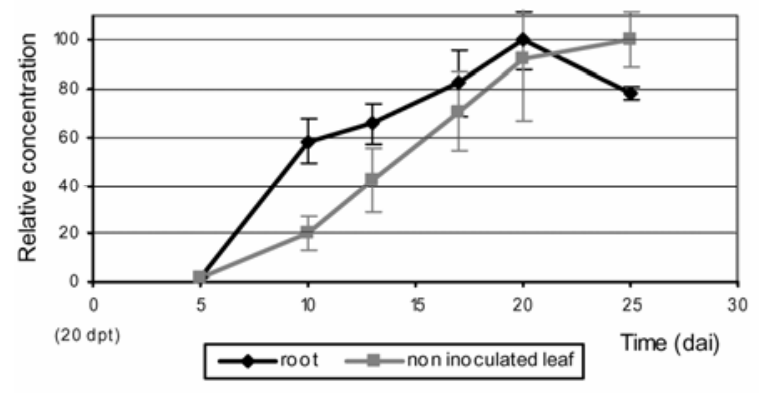

TuMV-UK1 inoculated in ESD7 mutant plants rcELISA

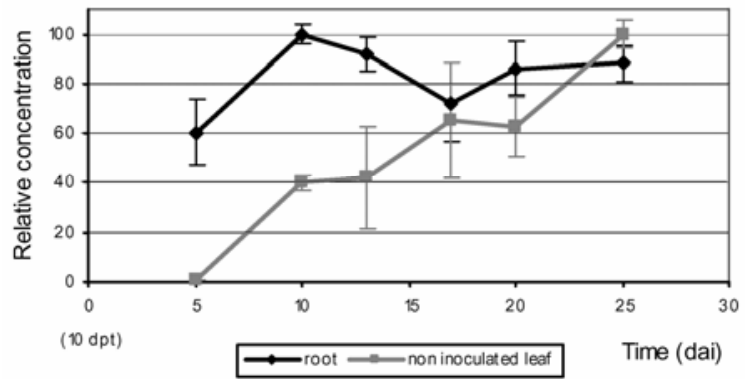

TuMN-UK1 inoculated in cry1 cry2 mutant plants _ rcelISA

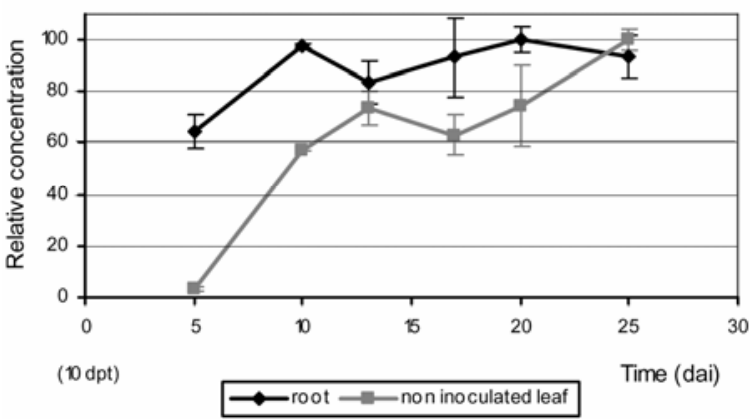

Fig. 4. Relative viral titters measured by relative concentration enzymelinked immunosorbent assay at different days after inoculation (dai) in roots and systemic leaves of Arabidopsis thaliana plants inoculated with Turnip mosaic virus (TuMV)-UK1. Inoculation time is 20 days posttransplantation (dpt) in the upper panel and $10 \mathrm{dpt}$ in the medium and lower panels. inoculation. The lower panel shows the results with the cryptochrome 1 and 2 (crylcry 2 ) double mutant, with a very late flowering time, which had not even formed the inflorescence bud at the normal time of the end of the experiment. The rcELISA curves obtained for both types of mutants were more or less similar, and again did not show any drop or halt in roots or leaves. These results strongly suggest that the processes of meristem transition from the vegetative state to the inflorescence state is correlated with a leveling or decline in the accumulation of virus components in roots and, to a lesser extent, in systemically infected leaves.

\section{DISCUSSION}

We have found that TuMV (a potyvirus) and ORMV (a tobamovirus), two (+)RNA plant viruses with different gene expression strategies, transiently undergo severe restrictions in their replication and accumulation in systemically invaded tissues of A. thaliana, both roots and aerial. This restriction is strictly temporal and time-linked to a specific developmental stage, the formation of the inflorescence bud. The finding is sustained by results from different experimental approaches, which can be combined in a descriptive model, summarized in Table 1. Because we find that the restriction phenomenon is notably more marked in root tissue, the descriptive model focuses mostly on virus fate in systemically invaded roots. However, where appropriate, allusions to systemically invaded aerial parts are made. A graphical summary of this descriptive model is presented in Supplemental Figure 3.

Viruses normally were inoculated onto a rosette leaf in plants at approximately growth stage 1.08 (Boyes et al. 2001), the start of phase A, that extended until 5 dai. Virus titer increased in roots at this phase more markedly for TuMV than for ORMV, which seems to be slower in reaching the roots. There was a 3to 4-day lag period between virus inoculation and first virus detections in the roots. Visual symptoms of virus infection were not still apparent in leaves at this stage, but the virus effect on plant development was already obvious. Thus, at the end of phase A, TuMV-infected plants were approximately at developmental stage 3.70, whereas parallel-run noninfected plants were already at stage 6.00. Phase A was longer for ORMV-infected plants (which did not exhibit a B phase), spanning a time period long enough to lead noninfected plants to approximately stage 6.50. ORMV-infected plants were approximately at developmental stage 5.10 at the end of phase A. In noninoculated leaves, TuMV still was not detectable by ELISA at the end of phase A. ORMV was ELISA detected at this time.

Phase B was found only in TuMV-infected plants. It is characterized by a high level of CP accumulation in the roots (approximately $100 \%$ of the maximum rcELISA reached) but a steep decrease in viral RNA susceptible to be RT-PCR amplified. Probably at this phase, TuMV RNA ceased its replication or accumulation, but new virions still arrived to root tissue. This interpretation reconciles the apparent contradiction of the

Table 1. Phases of a descriptive model proposed for the stages of virus-host interaction in Arabidopsis thaliana $a^{\mathrm{a}}$

\begin{tabular}{|c|c|c|}
\hline Phase & Accumulation pattern & Interpretation \\
\hline A & Virus accumulation (RNA and protein) & Virus arrives, replicates and assembles \\
\hline $\mathrm{B}$ & High capsid protein (CP) level, RNA level decreases & No viral RNA replication, no virion destruction, new virions keep arriving to roots \\
\hline $\mathrm{C}$ & $\mathrm{CP}$ protein level decreases, RNA level is maintained & $\begin{array}{l}\text { No viral RNA replication, limited (or no) virus arrival to roots, disorganization of } \\
\text { previously accumulated virions }\end{array}$ \\
\hline $\mathrm{D}$ & $\mathrm{CP}$ protein level increases, RNA level is maintained & Arrival of new virus to roots allowed, no viral RNA replication \\
\hline $\mathrm{E}$ & High RNA levels, slight CP level decrease & $\begin{array}{l}\text { Viral RNA replicates, possible ascending virus movement, regulation toward replication of } \\
\text { replication/translation balance }\end{array}$ \\
\hline $\mathrm{F}$ & $\begin{array}{l}\text { Final stage, senescence; viral RNA decreases, CP } \\
\text { levels are maintained }\end{array}$ & $\begin{array}{l}\text { Virus dependence on host development diminishes, likely influence of senescence- } \\
\text { associated degradative processes }\end{array}$ \\
\hline
\end{tabular}

${ }^{a}$ A plausible interpretation of the dynamic accumulation pattern observed for each stage also is provided. 
high rcELISA values and the abrupt fall in RNA detection, also consistent with the decrease of fluorescence of the GFP-tagged TuMV. In systemically infected leaves, CP rcELISA values just kept growing. The developmental stage of plants at the end of phase B was 5.10, whereas it was approximately 6.50 for noninfected plants.

Phase $\mathrm{C}$ covers the period of minimal viral activity in the infected roots. The $\mathrm{CP}$ accumulation level markedly lowered, and so did viral RNA. In addition, the fluorescence of viral-derived GFP also decreased notably in infected roots. Probably no viral RNA was replicated during this period. Alternatively, if RNA was being replicated, it was degraded at a higher rate, leading to a situation of global negative accumulation balance. The arrival of new virus to the roots probably is seriously limited. For TuMV, this would represent an important difference with phase $\mathrm{B}$, during which no RNA would be replicated but the accumulated CP level was still high. A low level of CP accumulation after having reached higher values would be compatible with this interpretation. However, it would not be sufficient. We are proposing that accumulated virions are disorganized and partially disassembled during this phase. The EM pictures obtained prompt this interpretation. Apparently, tobamovirus particles resisted the degradation process better but still went through some extent of disorganization as judged by EM particle density. We have no clue as to the type of cellular degradative environment mediating this root attack to virus multiplication and accumulation and at least partial virion destruction. It is worth mentioning in this context that virion-like forms of piled-up disks of TMV CP have been found in classical studies of Tobacco mosaic virus (TMV) in vitro assembly (Butler 1999; Stubbs 1999), showing that different types of TMV-like particles are experimentally possible under the appropriate conditions. Also, the state of Caspar carboxylates (critical chemical structures in TMV virion stability) is dependent on calcium and proton concentrations (Stubbs 1999). Thus, it is conceivable that different forms of ORMV particles also can exist in vivo under some developmentally linked physiological conditions.

In systemically infected leaves, no further $\mathrm{CP}$ accumulation was detected in phase $\mathrm{C}$ compared with levels already achieved, indicating that the virus restriction process also happened in leaves. This lack of increase also would be compatible with a transient halt in the arrival of new virus to the leaves. However, rcELISA values did not lower in leaves in phase $C$, suggesting that restriction in leaves did not include a virion degradation process. Phase $\mathrm{C}$ was time-linked to stage 5.10 (floral bud formation). Infected plants remained at this stage longer than their noninfected counterparts, which already had reached stage 6.90 at this time. At the end of phase $\mathrm{C}$, most infected plants were at approximately stage 6.30 , at the most.

Viral CP levels increased again at phase $\mathrm{D}$, in both roots and leaves. However, a parallel increase of viral RNA available for RT-PCR amplification did not take place. A plausible explanation for these uncoupled processes would be that new virus is allowed to arrive to virus sink tissues from infected source leaves, but the RNA replication or accumulation inhibition would still be operative. In any case, the results point to some level of independence between virus long-distance movement and viral RNA accumulation.

The period covered by the final phases $\mathrm{E}$ and $\mathrm{F}$ cannot be directly compared with developmental stages. In noninfected plants, this period is characterized mostly by the number of open flowers and the stage in the process of silique maturation. These processes do not take place in A. thaliana infected by these viruses, or they occur up to a very limited degree, such that it is not possible to evaluate them. At phase E, RNA accumulation would be restored, because the amount of RNA susceptible to be amplified by RT-PCR grew very quickly in both roots and leaves. The amount of detectable $\mathrm{CP}$ started a slow process of decrease, which would be compatible with several explanations, not mutually exclusive, such as a limited virus upward movement from the roots (unpublished results); limited virion degradation, possibly linked to the initiation of plant senescence of infected plants at these stages; or even a displacement toward replication in the replication/translation balance of available viral RNA. The final $\mathrm{F}$ phase would be marked by the decrease in accumulated viral RNA and maintenance of the reached CP levels. Infected plants exhibited severe symptoms at this stage, and plant tissues were massively senescing.

Globally considered, the descriptive model above basically illustrates the notion that, in the overall process of the interaction between viruses and their host plants, the interaction is mutually influential. We have found similar results with Brassica host plants (unpublished results). The idea that viruses utilize plant pathways and factors for the completion of their replication cycle and for host invasion is well established and exhaustively documented (Nelson and Citovsky 2005; Oparka 2004). Our results show that different phases of the viral life cycle in a compatible interaction with the host plant also are influenced and modified by particular plant developmental stages. It is almost impossible to invoke a single molecular, cellular, or physiological mechanism underlying the complex collection of events that the host plant seems to induce in the viral life cycle. It is more likely that a range of different mechanisms are used by the host plant to exert its influence.

However, none of our observations really require hitherto uncovered mechanisms. On the contrary, a precisely regulated combination of events and mechanisms already described in other contexts of plant physiology or plant virology would be sufficient to account for all the phases found. Thus, molecular mechanisms for the inhibition of virus replication and accumulation have been the subject of intense research in recent years, in the context of gene silencing as an antiviral mechanism in plants (Baulcombe 2004; Carrington et al. 2001; Dunoyer and Voinnet 2005; Lindbo and Dougherty 2005; Marathe et al. 2000; Vance and Vaucheret 2001; Voinnet 2005). Specifically, in roots, a process of silencing has been described for the interaction between TMV and $N$. benthamiana linked to the process of elongation of secondary root meristems (Valentine et al. 2002). Whether or not the link we find in A. thaliana between viral restriction and flower bud formation is the same process described for $N$. benthamiana in relation with secondary root elongation remains to be analyzed. Virion disorganization and disassembly is a more unexpected finding for tissues in which virions already are formed. Nevertheless, virions can be, and in fact are, disassembled constantly in the course of a systemic virus infection. When new virions arrive at an uninfected cell, they need to be disorganized and disassembled for the viral genome to be translated and replicated. The process has been described in detail for a few viruses and is well characterized for TMV (Butler 1999; Hull 2002). Of course, we do not know whether the virion disorganization that we find in the roots of infected plants is mechanistically related to the virion disassembly in newly infected cells; however, it illustrates that the plant cell is equipped with the molecular tools to carry it out.

Finally, our model needs to invoke a transient closure of systemically invaded tissues to the arrival of new viruses. There are well-studied examples of related processes in plant development. For instance, during A. thaliana development, there are changes in the communication in the symplasmic domains, initially corresponding to the major morphological regions of the plant (Kim and Zambryski 2005). Integration of several endogenous signals is required for floral induction (Wigge et al. 2005), and there are traffic changes of a fluorescent tracer during floral morphogenesis (Zambryski 2004). Symplasmic post- 
phloem domains have been found in A. thaliana roots (Stadler et al. 2005), the organs where we find the most dramatic changes in virus titers. We also recently have described how the movement protein of ORMV, transgenically expressed in A. thaliana, has marked differential effects on phloem unloading of a fluorescent tracer of phloem transport in different flower organs (Mansilla et al. 2006). Thus, virus systemic movement could add to the list of events regulated by symplasmic domains.

The temporal link between events in the apical meristem and viral restriction in other systemically infected organs, such as noninoculated leaves and roots, suggests that signals originated in the apical meristem can travel to these other tissues to influence viral replication or accumulation. Alternative explanations are also feasible; for example, that signals originating in leaves that influence meristem activity (Huang et al. 2005a; Martínez-García et al. 2002; Suárez-López 2005) have a side effect on virus infection. It also would be conceivable that root signals travel upward to influence both plant development and virus infection. At this time, we cannot favor or discard any of these possibilities (or a combination of them), which will need further characterization.

\section{MATERIALS AND METHODS}

\section{Plant material.}

A. thaliana plants ecotype RLD, the mutants ESD7 (supplied by J. A. Jarillo and M. Piñeiro) (unpublished data), and the crylcry2 double mutant (Mockler et al. 1999) were used in this work.

Arabidopsis seed were surface-sterilized for $10 \mathrm{~min}$ in $3 \%$ (vol/vol) sodium hypochlorite, $0.02 \%$ (vol/vol) Triton X-100, washed five to six times in sterile distilled water, sown in Murashige-Skoog medium, and kept for $24 \mathrm{~h}$ at $4^{\circ} \mathrm{C}$. After 10 to 12 days in a growth chamber (16-h photoperiod, light intensity $100 \mu \mathrm{E} \mathrm{m}^{-2} \mathrm{~s}^{-1}$, temperature $22^{\circ} \mathrm{C}$ ), plantlets were transplanted to soil in individual tray pots and maintained in a growth chamber with the same setting for temperature and light both before and after inoculation. Sampling was done at the times indicated in each experiment, taking care to not spoil any plant material. Special care was taken with roots, which were collected complete and carefully washed extensively to get rid of any remaining soil or vermiculite. Samples were weighed, frozen under liquid $\mathrm{N}_{2}$, and stored at $-80^{\circ} \mathrm{C}$ until analysis.

\section{Virus isolates, inoculation, and growth conditions.}

TuMV isolate UK1 and ORMV were maintained in infected A. thaliana plants. Plants were mechanically inoculated 10 days after transplantation to soil as described (Sánchez et al. 1998), in two rosette leaves at the eight-leaf stage of the plant (stage 1.08) (Boyes et al. 2001), except as varied to investigate different stages of plant development. Twelve plants were buffer-rubbed as controls.

\section{Viral capsid antigen accumulation.}

Quantification of capsid antigen of each virus was accomplished by ELISA. Time-course analyses were performed in four independent assays, sampling six to nine plants each time. Each sample (complete roots or noninoculated leaves) was weighted, frozen under liquid nitrogen, and stored at $-80^{\circ} \mathrm{C}$ until its analysis. Commercial Agdia systems were used in the ELISAs, with a monoclonal AntiPotyvirus for the detection of TuMV and a polyclonal antibody directed against Ribgrass mosaic virus (RMV) for ORMV (that strongly cross-reacts with ORMV). Each sample was ground 1:10 (wt/vol) in extraction buffer for the ELISA. In addition to the extracts of infected tissues, plates included extracts from five noninoculated plants. In- terplate variability was dealt with through the use of rcELISA (Conci et al. 2002).

\section{GFP detection.}

An infectious TuMV-GFP cDNA clone was prepared in which the GFP gene had been inserted between the NIb and $\mathrm{CP}$ genes. This clone (unpublished data) was derived from the original TuMV infectious clone and used as described (Sánchez et al. 1998). Fluorescence was observed under an inverted epifluorescence microscope (Leica Microsystems, Wetzlar, Germany) using an FITC filter.

\section{Electron microscope analyses.}

Leaf dips plus decoration were performed as described (Milne and Luisoni 1977), with minor modifications. Briefly, carbon-filmed grids were incubated in $10 \mu \mathrm{l}$ of infected root plant extracts and kept at $20^{\circ} \mathrm{C}$ for $15 \mathrm{~min}$. Grids then were washed with $0.05 \mathrm{M} \mathrm{Na}_{2} \mathrm{~B}_{4} \mathrm{O}_{7}$ and incubated with anti-TuMV (Loewe, Sauerlach, Germany) or anti-RMV (Agdia, Elkhart, IN, U.S.A.) antibodies diluted $1: 25$ for $10 \mathrm{~min}$ at $20^{\circ} \mathrm{C}$. Finally, they were washed with distilled water and stained for 2 min with $2 \%$ uranyl acetate.

Virions were analyzed in a transmission electron microscope (EM Jeol 1010, Jeol, Tokyo). Two parameters were measured: length and relative density. Length was measured directly in the EM micrographs. Relative density was calculated relative to the color intensity of several sections of the virion images relative to their corresponding background intensities. For the calculations, measurements were done in micrographs taken at the same magnification, considering a constant circular measurement area (three to four measurements per virion). Approximately 60 virions were measured for both viruses. Relative values obtained with respect to their background allowed the comparison of different images. Image analysis was done with Adobe Photoshop.

\section{Viral RNA accumulation.}

RNA extracts were prepared from virus-infected plants using the RNeasy plant mini kit (Qiagen, Basel, Switzerland). RTqPCR was performed as described (Lunello et al. 2004). TuMV primers (within the CP cistron) were $\left(5^{\prime} \rightarrow 3^{\prime}\right)$ forward TGTTCGGCTTGGATGGAA, reverse TTAACGTCCTCGGT CGTATGC, and probe 6FAM-CGTTGGTACAACGGTAGAG AACACGGAGA. ORMV primers (flanking the $3^{\prime}$ terminal region of the replicase cistron plus the $5^{\prime}$ terminal region of the polymerase domain) were forward GAAAGAACGGCCG GTTTTC, reverse CCAGCAGTTCGTGGCATTT, and probe 6FAM-TGAAACCTAAATTGAGGACGGCGGC.

For estimates of absolute viral RNA amounts, an internal control (serial dilutions with replicates of plasmid p35Tunos of known concentrations) (Sánchez et al. 1998) was included in each qPCR plate.

\section{ACKNOWLEDGMENTS}

This work was funded in part by grants BIO2002-02191 and BIO200304516 of the Spanish granting agency CICYT. P. Lunello was the recipient of a postdoctoral fellowship from CONICET (Argentina), and C. Mansilla was the recipient of a predoctoral INIA fellowship. We thank J. A. Jarillo and M. Piñeiro for their kind gifts of the A. thaliana flowering-time mutants. Comments and suggestions from G. Bruening (University of California, Davis, U.S.A.) greatly contributed to the improvement of this manuscript.

\section{LITERATURE CITED}

Aguilar, I., Sánchez, F., Martín, A. M., Martínez-Herrera, D., and Ponz, F. 1996. Nucleotide sequence of Chinese rape mosaic virus (Oilseed rape 
mosaic virus), a crucifer tobamovirus infectious on Arabidopsis thaliana. Plant Mol. Biol. 30:191-197.

Baulcombe, D. 2004. RNA silencing in plants. Nature 431:356-363.

Boevink, P., and Oparka, K. J. 2005. Virus-host interactions during movement processes. Plant Physiol. 138:1815-1821.

Boyes, D. C., Zayed, A. M., Ascenzi, R., McCaskill, A. J., Hoffman, N. E., Davis, K. R., and Gorlach, J. 2001. Growth stage-based phenotypic analysis of Arabidopsis: A model for high throughput functional genomics in plants. Plant Cell 13:1499-1510.

Butler, P. J. G. 1999. Self-assembly of Tobacco mosaic virus: The role of an intermediate aggregate in generating both specificity and speed. Phil. Trans. R. Soc. B 354:537-550.

Carrington, J. C., Kasschau, K. D., Mahajan, S. K., and Schaad, M. C. 1996. Cell-to-cell and long-distance transport of viruses in plants. Plant Cell 8:1669-1681.

Carrington, J. C., Kasschau, K. D., and Johansen, L. K. 2001. Activation and suppression of RNA silencing by plant viruses. Virology 281:1-5.

Conci, V. C., Lunello, P., Buraschi, D., Italia, R. R., and Nome, S. F. 2002. Variations of Leek yellow stripe virus concentration in garlic and its incidence in Argentina. Plant Dis. 86:1085-1088.

Dunford, S. 2006. Translocation in the phloem. Pages 227-228 in: Plant Physiology. L. Taiz and E. Zeiger, ed. Sinauer Associates, Inc., Sunderland, MA, U.S.A.

Dunoyer, P., and Voinnet, O. 2005. The complex interplay between plant viruses and host RNA-silencing pathways. Curr. Opin. Plant. Biol. 8:415-423.

Dunoyer, P., Thomas, C., Harrison, S., Revers, F., and Maule, A. 2004. A cysteine-rich plant protein potentiates Potyvirus movement through an interaction with the virus genome-linked protein VPg. J. Virol. 78:23012309.

Huang, T., Bohlenius, H., Eriksson, S., Parcy, F., and Nilsson, O. 2005a. The mRNA of the Arabidopsis gene FT moves from leaf to shoot apex and induces flowering. Science 309:1694-1696.

Huang, Z. L., Yeakley, J. M., Garcia, E. W., Holdridge, J. D., Fan, J. B., and Whitham, S. A. 2005b. Salicylic acid-dependent expression of host genes in compatible Arabidopsis-virus interactions. Plant Physiol. 137:1147-1159.

Hull, R. 2002. Architecture and assembly of virus particles. Pages 109-169 in: Matthew's Plant Virology, fourth ed. Academic Press, London.

Jenner, C. E., Sánchez, F., Nettleship, S. B., Foster, G. D., Ponz, F., and Walsh, J. A. 2000. The cylindrical inclusion gene of Turnip mosaic virus encodes a pathogenic determinant to the Brassica resistance gene TuRB01. Mol. Plant-Microbe Interact. 13:1102-1108.

Kaneko, Y., Inukai, T., Suehiro, N., Natsuaki, T., and Masuta, C. 2004 Fine genetic mapping of the TuNI locus causing systemic veinal necrosis by Turnip mosaic virus infection in Arabidopsis thaliana. Theor. Appl. Genet. 110:33-40.

Kim, I., and Zambryski, P. C. 2005. Cell-to-cell communication via plasmodesmata during Arabidopsis embryogenesis. Curr. Opin. Plant. Biol. 8:593-599.

Leisner, S. M., and Howell, S. H. 1993. Long-distance movement of viruses in plants. Trends Microbiol. 1:314-317.

Leisner, S. M., and Turgeon, R. 1993. Movement of virus and photoassimilate in the phloem-a comparative analysis. Bioessays 15:741-748.

Leisner, S. M., Turgeon, R., and Howell, S. H. 1993. Effects of host plant development and genetic determinants on the long distance movement of Cauliflower mosaic virus in Arabidopsis. Plant Cell 5:191-202.

Leonard, S., Viel, C., Beauchemin, C., Daigneault, N., Fortin, M. G., and Laliberte, J. F. 2004. Interaction of VPg-Pro of Turnip mosaic virus with the translation initiation factor $4 \mathrm{E}$ and the poly(A)-binding protein in planta. J. Gen. Virol. 85:1055-1063.

Lindbo, J. A., and Dougherty, W. G. 2005. Plant pathology and RNAi: A brief history. Annu. Rev. Phytopathol. 43:191-204.

Lunello, P., Mansilla, C., Conci, V., and Ponz, F. 2004. Ultra-sensitive detection of two garlic potyviruses using a real-time fluorescent (Taqman) RT-PCR assay. J. Virol. Methods 118:15-21.

Mansilla, C., Aguilar, I., Martínez-Herrera, D., Sánchez, F., and Ponz, F. 2006. Physiological effects of constitutive expression of Oilseed rape mosaic tobamovirus (ORMV) movement protein in Arabidopsis thaliana. Transgenic Res. 15:761-770.

Marathe, R., Anandalakshmi, R., Smith, T. H., Pruss, G. J., and Vance, V. B. 2000. RNA viruses as inducers, suppressors and targets of post-transcriptional gene silencing. Plant Mol. Biol. 43:295-306.

Martínez-García, J. F., Virgos-Soler, A., and Prat, S. 2002. Control of photoperiod-regulated tuberization in potato by the Arabidopsis floweringtime gene CONSTANS. Proc. Natl. Acad. Sci. U.S.A. 99:15211-15216.

Melcher, U. 2003. Turnip vein clearing virus, from pathogen to host expression profile. Mol. Plant Pathol. 4:133-140.

Milne, R. G., and Luisoni, E. 1977. Serological relationships among maize rough dwarf-like viruses. Virology 80:12-20.

Mockler, T., Guo, H., Yang, H., Duong, H., and Lin, C. 1999. Antagonistic actions of Arabidopsis cryptochromes and phytochrome B in the regulation of floral induction. Development 126:2073-2082.

Nelson, R. S., and Citovsky, V. 2005. Plant viruses. Invaders of cells and pirates of cellular pathways. Plant Physiol. 138:1809-1814.

Oparka, K. J. 2004. Getting the message across: How do plant cells exchange macromolecular complexes? Trends Plant Sci. 9:33-41.

Oparka, K. J., and Santa Cruz, S. 2000. The great escape: Phloem transport and unloading of macromolecules. Annu. Rev. Plant Physiol. Plant Mol. Biol. 51:323-347.

Oparka, K. J., Roberts, A. G., Boevink, P., Santa Cruz, S., Roberts, L., Pradel, K. S., Imlau, A., Kotlizky, G., Sauer, N., and Epel, B. 1999. Simple, but not branched, plasmodesmata allow the nonspecific trafficking of proteins in developing tobacco leaves. Cell 97:743-754.

Palukaitis, P. 1987. Potato spindle tuber viroid: Investigation of the longdistance, intra-plant transport route. Virology 158:239-241.

Plante, D., Viel, C., Leonard, S., Tampo, H., Laliberte, J. F., and Fortin, M. G. 2004. Turnip mosaic virus VPg does not disrupt the translation initiation complex but interferes with cap binding. Physiol. Mol. Plant Pathol. 64:219-226.

Qi, Y. J., Pelissier, T., Itaya, A., Hunt, E., Wassenegger, M., and Ding, B. 2004. Direct role of a viroid RNA motif in mediating directional RNA trafficking across a specific cellular boundary. Plant Cell 16:1741-1752.

Roberts, A. G., Santa Cruz, S., Roberts, I. M., Prior, D. A. M., Turgeon, R., and Oparka, K. J. 1997. Phloem unloading in sink leaves of Nicotiana benthamiana: Comparison of a fluorescent solute with a fluorescent virus. Plant Cell 9:1381-1396.

Samuel, G. 1934. The movement of Tobacco mosaic virus within the plant. Ann. Appl. Biol. 21:90-111.

Sánchez, F., Martínez-Herrera, D., Aguilar, I., and Ponz, F. 1998. Infectivity of Turnip mosaic potyvirus cDNA clones and transcripts on the systemic host Arabidopsis thaliana and local lesion hosts. Virus Res. 55:207-219.

Sato, M., Nakahara, K., Yoshii, M., Ishikawa, M., and Uyeda, I. 2005. Selective involvement of members of the eukaryotic initiation factor $4 \mathrm{E}$ family in the infection of Arabidopsis thaliana by potyviruses. FEBS (Fed. Eur. Biochem. Soc.) Lett. 579:1167-1171.

Stadler, R., Wright, K. M., Lauterbach, C., Amon, G., Gahrtz, M., Feuerstein, A., Oparka, K. J., and Sauer, N. 2005. Expression of GFPfusions in Arabidopsis companion cells reveals non-specific protein trafficking into sieve elements and identifies a novel post-phloem domain in roots. Plant $\mathrm{J}$. 41:319-331.

Stubbs, G. 1999. Tobacco mosaic virus particles: Structure and the initiation of disassembly. Phil. Trans. R. Soc. B Biol. Sci. 354:551-557.

Suárez-López, P. 2005. Long-range signalling in plant reproductive development. Int. J. Dev. Biol. 49:761-771.

Suehiro, N., Natsuaki, T., Watanabe, T., and Okuda, S. 2004. An important determinant of the ability of Turnip mosaic virus to infect Brassica spp. and/or Raphanus sativus is in its P3 protein. J. Gen. Virol. 85:20872098

Tan, Z. Y., Gibbs, A. J., Tomitaka, Y., Sanchez, F., Ponz, F., and Ohshima, K. 2005. Mutations in Turnip mosaic virus genomes that have adapted to Raphanus sativus. J. Gen. Virol. 86:501-510.

Valentine, T. A., Roberts, I. M., and Oparka, K. J. 2002. Inhibition of Tobacco mosaic virus replication in lateral roots is dependent on an activated meristem-derived signal. Protoplasma 219:184-196.

Vance, V., and Vaucheret, H. 2001. RNA silencing in plants-defense and counterdefense. Science 292:2277-2280.

Voinnet, O. 2005. Induction and suppression of RNA silencing: Insights from viral infections. Nat. Rev. Genet. 6:206-220.

Waigmann, E., Ueki, S., Trutnyeva, K., and Citovsky, V. 2004. The ins and outs of nondestructive cell-to-cell and systemic movement of plant viruses. Crit. Rev. Plant Sci. 23:195-250.

Walsh, J. A., and Jenner, C. E. 2002. Turnip mosaic virus and the quest for durable resistance. Mol. Plant Pathol. 3:289.

Whitham, S. A., Quan, S., Chang, H. S., Cooper, B., Estes, B., Zhu, T., Wang, X., and Hou, Y. M. 2003. Diverse RNA viruses elicit the expression of common sets of genes in susceptible Arabidopsis thaliana plants. Plant J. 33:271-283.

Wigge, P. A., Kim, M. C., Jaeger, K. E., Busch, W., Schmid, M., Lohmann, J. U., and Weigel, D. 2005. Integration of spatial and temporal information during floral induction in Arabidopsis. Science 309:1056-1059.

Zambryski, P. 2004. Cell-to-cell transport of proteins and fluorescent tracers via plasmodesmata during plant development. J. Cell Biol. 164:165-168.

\section{AUTHOR-RECOMMENDED INTERNET RESOURCE}

The Arabidopsis Information Resource website: www.arabidopsis.org 